\title{
Pain involving the motor system and serum vitamin $D$ concentration in postmenopausal women working in agriculture
}

\author{
Dorota Raczkiewicz1, Alfred Owoc ${ }^{2}$, Beata Sarecka-Hujar³, Iwona Bojar 4 \\ ${ }^{1}$ Institute of Statistics and Demography, Warsaw School of Economics, Warsaw, Poland \\ ${ }^{2}$ Center for Public Health and Health Promotion, Institute of Rural Health in Lublin, Poland \\ ${ }^{3}$ Medical University of Silesia in Katowice, School of Pharmacy with the Division of Laboratory Medicine in Sosnowiec, \\ Department of Pharmaceutical Technology, Chair of Applied Pharmacy, Sosnowiec, Poland \\ ${ }^{4}$ Institute of Rural Health in Lublin, Department for Woman Health, Lublin, Poland
}

Raczkiewicz D, Owoc A, Sarecka-Hujar B, Bojar I. Pain involving the motor system and serum vitamin D concentration in postmenopausal women working in agriculture. Ann Agric Environ Med. 2017; 24(1): 151-155.

\begin{abstract}
Introduction and objective. Since the role of vitamin D is essential in numerous biological processes its deficiency was suggested to be a risk factor for e.g. osteoporosis, musculoskeletal pain and spine pain. The purpose of the study was to analyse whether serum vitamin D concentration is related to pain involving the motor system in Polish postmenopausal women working in agriculture.

Material and methods. The study group consisted of 1,751 post-menopausal women, aged $45-65$, at least 12 months from the last menstrual period, living in rural areas and working in agriculture. The research method was self-assessment of pain involving the motor system using VAS, laboratory test of serum vitamin D concentration and a medical interview. Statistical methods included generalized linear models, analysis of variance, $t$ test for two means in two independents, $\mathrm{X}^{2}$ test of stochastic independence.

Results. Postmenopausal women working in agriculture and suffering from pain in at least one part of the motor system were younger and lower educated, they also had higher abdominal obesity and lower serum vitamin $\mathrm{D}$, compared to those without pain in any part of the motor system. Decreased serum vitamin D concentration in postmenopausal women working in agriculture is important from the aspect of a higher prevalence of pain in the thoracic spine and more severe pain in the neck spine, but not for severity of pain in the lumbar spine; higher occurrence of pain in both hands or wrists; higher prevalence and more severe pain in at least one knee; and no prevalence or severity of pain in the shoulders and elbows.
\end{abstract}

Conclusion. Serum vitamin D concentration is important for the prevalence and severity of pain in the neck and thoracic spine, knees and hands or wrists, but not for the lumbar spine, shoulders and elbows.

\section{Key words}

menopause, vitamin D, pain, motor system

\section{INTRODUCTION}

The role of vitamin $\mathrm{D}$ is essential not only in bone metabolism but also in numerous biological processes. Vitamin D deficiency was suggested to be a risk factor for the development of many diseases, including osteoporosis, musculoskeletal and spine pain. Vitamin D, produced both in the skin and derived from the diet is hydroxylated in the liver by one of several cytochrome P450 enzymes to 25-hydroxy Vitamin D (calcidiol, or 25-OHD) [1]. The $1 \alpha$-hydroxylase enzyme is the main enzyme catalysing the conversion of circulating 25-hydroxyvitamin D3 (25-OHD) to $1,25-\mathrm{OHD}$, and is expressed predominantly in the kidneys as well as in other tissues. The 1,25-OHD is involved in the regulation of numerous genes responsible for cellular proliferation, differentiation, apoptosis and angiogenesis [2]. Serum 25-hydroxyvitamin D declines with age [3] and vitamin $\mathrm{D}$ deficiency is thought to contribute to bone loss in

Address for correspondence: Dorota Raczkiewicz, Institute of Statistics and Demography, Warsaw School of Economics, Niepodleglosci 162, 02-554 Warsaw, Poland

E-mail: dbartos@sgh.waw.pl

Received: 9 March 2017; Accepted: 14 March 2017; first published on March 2017 women, especially after menopause. Deficiency of vitamin $\mathrm{D}$ is typically found in the countries with insufficient sun exposure during the winter months. In the study of Siddque et al. [4], low levels of vitamin D were found in $81 \%$ of low back pain patients. Similar results were demonstrated in a study from Saudi Arabia; however, after treatment, 95\% of patients with low back pain showed significant improvement in the serum concentrations of vitamin D [5].

In order to avoid spine pain, strengthening of the back and musculoskeletal system by means of a special diet and supplementation with vitamin $\mathrm{D}$ is fundamental. In patients with chronic back pain from India, the supplementation of vitamin D was increased from $12.8 \mathrm{ng} / \mathrm{ml}-36.07 \mathrm{ng} / \mathrm{ml}$ and may have led to a reduction in pain intensity [6].

Pain involving the motor system (neck, thoracic and lumbar spine, shoulders, elbows, hands, wrists and knees) is a serious medical problem. This is noteworthy especially in postmenopausal women, since they are more exposed to osteoporosis due to age and low oestrogen levels. Women working in agriculture are additionally exposed to hard physical work, resulting in spine overload and, in turn, pain. In a large group of postmenopausal women, Grigorie et al. [7] observed that in $83.49 \%$ the levels of vitamin D were lower 
than $30 \mathrm{ng} / \mathrm{ml}$ and in $60.97 \%$ lower than $20 \mathrm{ng} / \mathrm{ml}$. Previously, vitamin $\mathrm{D}$ deficiency was reported as the main determinant of chronic lower back pain in Moroccan postmenopausal women with the OR value equal to 2.5 [8].

The purpose of the study was to analyse whether serum vitamin $\mathrm{D}$ concentration is related to pain involving the motor system in Polish postmenopausal women working in agriculture.

\section{MATERIAL AND METHODS}

Study group. The study was conducted in 2016 in Poland and included 1,751 randomly-selected post-menopausal women, living in rural areas and working in agriculture. The inclusion criteria were: age 45-65 and at least 12 months from the last menstrual period. The exclusion criteria were addiction to drugs or/and alcohol, and a diagnosed disease entity with the symptoms of dementia. The women were asked about age, date of the last menstrual period, level of education, body weight and height, waist and hips circumference, parity and number of births. The total group of examined women was divided into two subgroups, with and without pain, according to the presence of pain involving at least one part of their motor system.

Self-assessment of pain in the motor system. The women assessed the presence and severity of pain in seven parts of their motor system: three sections of spine: neck, thoracic and lumbar, as well as in the shoulders, elbows, hands or wrists and knees, and separate left and right sides of the body. The severity of pain was assessed in the VAS (Visual Analogue Scale) which ranged from 0 (no pain) to 10 (the worst pain - unbearable). If both shoulders, elbows, hands or wrists and knees were painful, the maximum severity of the pain was used for analyses.

Laboratory test of serum vitamin D concentration. Peripheral blood was collected from all the women for tests in accredited laboratories of the concentrations of vitamin $\mathrm{D}$ in the blood serum. Standard ranges of vitamin $\mathrm{D}$ were as follows: deficit $(<10 \mathrm{ng} / \mathrm{ml})$, deficiency $(10-20 \mathrm{ng} / \mathrm{ml})$, hypovitaminosis $(20-30 \mathrm{ng} / \mathrm{ml})$ and desirable $(30-80 \mathrm{ng} / \mathrm{ml})$. The first three vitamin $\mathrm{D}$ ranges were combined into one -'below desirable' for the selected analyzes.

Statistical analysis. The results were statistically analysed by SAS System software. Mean values (M) with standard deviations (SD) for continuous variables, and absolute (n) and relative numbers (\%) of occurrence of items for categorical variables were estimated.

For characteristics, the $\mathrm{t}$ test for two means in two independent samples was used to compare continuous variables, and the $\chi 2$ test to compare categorical variables between women with pain in at least one part of their motor system and without pain in any part.

The $\chi 2$ test was used to compare the prevalence of pain in particular parts of the motor system between the women with vitamin D below the desirable level and with vitamin $\mathrm{D}$ at the desirable level. F test analysis of variance was used to compare the severity of pain in particular parts of the motor system among the women with vitamin D in four groups: deficit, insufficiency, hypovitaminosis and desirable.
Generalized linear models of vitamin D concentration vs. prevalence and severity of pain in particular parts of the motor system were also estimated in which a normal distribution of vitamin $\mathrm{D}$ concentration and identity link function was assumed. We estimated slope terms (b), i.e. mean differences in vitamin $\mathrm{D}$ concentration between women with and without pain in particular parts of the motor system (in the first model), and mean change of vitamin D concentration connected with one point change of severity of pain in particular parts of the motor system (in the second model), on average, ceteris paribus.

The value of $\mathrm{p}<0.05$ is considered as a significant difference.

Informed consent for participation in the study was obtained from the women. The study was approved by the Ethics Committee at the Institute of Rural Medicine in Lublin, Poland.

\section{RESULTS}

Characteristics of the study group. 1,751 post-menopausal women working in agriculture were examined, of whom $1,327(75.8 \%)$ suffered from pain involving at least one part of the motor system, and $424(24.2 \%)$ did not feel pain in any part of the system.

The women suffering from pain involving at least one part of the motor system were younger and lower-educated, they also had higher abdominal obesity and lower serum vitamin $\mathrm{D}$ concentration, compared to those without pain in any part of the motor system. The BMI, age at the last menstruation, parity and number of births were not significantly different between the women with and without pain involving their motor system (Tab.1).

Prevalence and severity of pain involving the motor system vs. vitamin D groups. $2 / 3$ of the examined women suffered from pain involving at least one section of the spine, most commonly in the lumbar part, less commonly in the cervical part, and the least common in the thoracic part. Every third of the examined women felt pain in at least one knee, every fifth in at least one shoulder, and almost the same number in at least one hand or wrist, and every tenth in at least one elbow. If the examined women felt pain in the shoulders, it was more commonly on one side of the body than two. If they felt pain in the elbows, similarly, it was more usual on one side of the body than two. If pain was experienced in the hands or wrists and knees, it was more commonly on both sides of the body than one.

The women with vitamin $\mathrm{D}$ level below the desirable concentration more commonly suffered from pain in the thoracic spine and both hands or wrists than those with desirable vitamin $\mathrm{D}$ concentration (Tab. 2).

The examined women felt the most severe pain in the lumbar spine, and the least in the elbows. Pain in the cervical spine was significantly the most severe in the examined women with a deficit of vitamin $\mathrm{D}$, and the least severe in those with the desirable serum concentration of vitamin D. Pain in at least one knee was significantly more severe in the examined women with a deficit of vitamin $\mathrm{D}$ than in the rest of the woman (Tab. 3).

Vitamin D ( $\mathrm{ng} / \mathrm{ml})$ vs. prevalence and severity of pain in the motor system. The women who suffered from pain in at 
Table 1. Characteristics of the examined women

\begin{tabular}{|c|c|c|c|c|}
\hline Characteristics & Total $(\mathrm{N}=1751)$ & $\begin{array}{l}\text { Women with pain involving the motor system } \\
\qquad(\mathrm{N}=1327)\end{array}$ & $\begin{array}{l}\text { Women without pain Involving the motor system } \\
\qquad(\mathrm{N}=424)\end{array}$ & $\mathrm{p}$ \\
\hline Age (years), $M \pm S D$ & $57.0 \pm 4.6$ & $56.7 \pm 4.5$ & $57.9 \pm 4.7$ & \multirow{5}{*}{$<0.001$} \\
\hline $45-49, \mathrm{n}(\%)$ & $105(6.0)$ & $80(6.0)$ & $25(5.9)$ & \\
\hline $50-54$ & $418(23.9)$ & $347(26.2)$ & $71(16.8)$ & \\
\hline $55-59$ & $680(38.8)$ & $521(39.3)$ & $159(37.5)$ & \\
\hline $60-65$ & $548(31.3)$ & $379(28.6)$ & $169(39.9)$ & \\
\hline \multicolumn{5}{|l|}{ Education level, n (\%) } \\
\hline primary not completed or no education & $34(1.9)$ & $20(1.5)$ & $14(3.3)$ & \multirow{5}{*}{$<0.001$} \\
\hline primary & $337(19.2)$ & $233(17.6)$ & $104(24.5)$ & \\
\hline basic vocational & $657(37.5)$ & $489(36.9)$ & $168(39.6)$ & \\
\hline secondary & $673(38.4)$ & $540(40.7)$ & $133(31.4)$ & \\
\hline tertiary & $50(2.9)$ & $45(3.4)$ & $5(1.2)$ & \\
\hline $\mathrm{BMI}(\mathrm{kg} / \mathrm{m} 2), \mathrm{M} \pm \mathrm{SD}$ & $29.7 \pm 5.4$ & $29.6 \pm 5.4$ & $29.7 \pm 5.2$ & \multirow{4}{*}{$\begin{array}{l}0.850 \\
0.448^{*}\end{array}$} \\
\hline underweight, n (\%) & $8(0.5)$ & $4(0.3)$ & $4(0.9)$ & \\
\hline normal & $329(18.8)$ & $258(19.4)$ & $71(16.8)$ & \\
\hline obese & $748(42.7)$ & $567(42.7)$ & $181(42.7)$ & \\
\hline $\mathrm{WHR}(\%), \mathrm{M} \pm \mathrm{SD}$ & $87.2 \pm 6.9$ & $87.4 \pm 6.9$ & $86.6 \pm 7.0$ & \multirow{3}{*}{0.042} \\
\hline$<0.85, \mathrm{n}(\%)$ & $669(38.2)$ & $495(37.3)$ & $174(41.0)$ & \\
\hline$\geq 0.85$ & $1082(61.8)$ & $832(62.7)$ & $250(59.0)$ & \\
\hline Age at last menstruation (years), $\mathrm{M} \pm \mathrm{SD}$ & $49.1 \pm 3.8$ & $49.1 \pm 3.8$ & $49.1 \pm 3.5$ & 0.982 \\
\hline \multicolumn{5}{|l|}{ Menopause, n (\%) } \\
\hline early (up to 45 years) & $263(18.1)$ & $210(18.5)$ & $53(16.9)$ & \multirow{3}{*}{$0.518^{*}$} \\
\hline normal (46-55 years) & $1179(81.3)$ & $920(80.8)$ & $259(82.8)$ & \\
\hline late $(56+$ years $)$ & $9(0.6)$ & $8(0.7)$ & $1(0.3)$ & \\
\hline \multicolumn{5}{|l|}{ Parity, n (\%) } \\
\hline yes & $1686(97.1)$ & $1280(97.0)$ & $406(974)$ & \multirow[t]{2}{*}{0.734} \\
\hline no & $50(2.9)$ & $39(3.0)$ & $11(2.6)$ & \\
\hline Number of births, $\mathrm{M} \pm \mathrm{SD}$ & $2.9 \pm 1.3$ & $2.9 \pm 1.3$ & $2.8 \pm 1.2$ & 0.218 \\
\hline Vitamin D concentration (ng/ml), M $\pm \mathrm{SD}$ & $25.1 \pm 9.3$ & $24.9 \pm 9.2$ & $26.0 \pm 9.8$ & \multirow{3}{*}{0.033} \\
\hline deficit (<10 ng/ml), n (\%) & $46(2.6)$ & $40(3.0)$ & $6(1.4)$ & \\
\hline desirable $(30-80 \mathrm{ng} / \mathrm{ml})$ & $467(26.7)$ & $347(26.2)$ & $120(28.3)$ & \\
\hline
\end{tabular}

$\mathrm{p}$ - Student $\mathrm{t}$ test for continuous variables or $\mathrm{x}^{2}$ test for categorical variables.

* - tested without BMI underweight and late menopause due to small sample size.

Table 2. Prevalence of pain involving the motor system vs. vitamin D levels in the examined women

\begin{tabular}{|c|c|c|c|c|c|}
\hline \multirow{2}{*}{ Part of the motor system } & \multirow{2}{*}{ Section/number } & Total $(\mathrm{N}=1751)$ & Vitamin $\mathrm{D}$ below desirable $(\mathrm{N}=1284)$ & Vitamin $\mathrm{D}$ desirable $(\mathrm{N}=467)$ & \multirow{2}{*}{$\mathrm{p}$} \\
\hline & & $\mathrm{n}(\%)$ & n (\%) & $\mathrm{n}(\%)$ & \\
\hline \multirow{4}{*}{ Spine } & at least one section & $1161(66.3)$ & $850(66.2)$ & $311(66.6)$ & 0.877 \\
\hline & Cervical & $669(38.2)$ & $492(38.3)$ & 177 (37.9) & 0.874 \\
\hline & Thoracic & $289(16.5)$ & $199(15.5)$ & $90(19.3)$ & 0.050 \\
\hline & Lumbar & $941(53.7)$ & $693(54.0)$ & $248(53.1)$ & 0.748 \\
\hline Shoulder/s & only one & $200(11.4)$ & $146(11.4)$ & $54(11.6)$ & \multirow{2}{*}{0.993} \\
\hline & both & $158(9.0)$ & $116(9.0)$ & $42(9.0)$ & \\
\hline \multirow{3}{*}{ Elbow/s } & at least one & $175(10.0)$ & $127(9.9)$ & $48(10.3)$ & \\
\hline & only one & $87(5.0)$ & $57(4.4)$ & $30(6.4)$ & \multirow{2}{*}{0.108} \\
\hline & both & $88(5.0)$ & $70(5.5)$ & $18(3.9)$ & \\
\hline \multirow[t]{2}{*}{ Hand(s) /wrist(s) } & only one & $129(7.4)$ & $89(6.9)$ & $40(8.6)$ & \multirow{2}{*}{0.018} \\
\hline & both & $189(10.8)$ & $154(12.0)$ & $37(7.5)$ & \\
\hline \multirow{3}{*}{ Knee(s) } & at least one & 559 (31.9) & $421(33.8)$ & 138 (29.6) & \\
\hline & only one & $258(14.7)$ & $195(15.2)$ & $63(13.5)$ & \multirow{2}{*}{0.434} \\
\hline & both & $301(17.2)$ & $226(17.6)$ & 75 (16.1) & \\
\hline
\end{tabular}

$p$ - test $x^{2}$ 
Table 3. Severity of pain in the motor system vs. vitamin D levels in the examined women

\begin{tabular}{|c|c|c|c|c|c|c|}
\hline \multirow{3}{*}{$\begin{array}{l}\text { Part of the } \\
\text { motor system }\end{array}$} & \multirow[b]{2}{*}{ Total } & \multicolumn{4}{|c|}{ Vitamin D } & \multirow{3}{*}{$\mathrm{p}$} \\
\hline & & deficit & deficiency & $\begin{array}{c}\text { hypo- } \\
\text { vitaminosis }\end{array}$ & desirable & \\
\hline & \multicolumn{5}{|c|}{ Severity of pain $(M \pm S D)$} & \\
\hline Cervical spine & $5.5 \pm 2.0$ & $5.9 \pm 2.1$ & $5.4 \pm 1.9$ & $5.8 \pm 2.1$ & $5.3 \pm 1.9$ & 0.050 \\
\hline Thoracic spine & $5.5 \pm 2.1$ & $4.0 \pm 2.4$ & $5.7 \pm 2.0$ & $5.6 \pm 2.1$ & $5.2 \pm 2.0$ & 0.223 \\
\hline Lumbar spine & $6.0 \pm 2.1$ & $6.2 \pm 2.2$ & $5.9 \pm 2.1$ & $6.0 \pm 2.1$ & $5.9 \pm 2.0$ & 0.725 \\
\hline Shoulder(s)i* & $5.8 \pm 2.2$ & $6.0 \pm 2.2$ & $5.8 \pm 2.1$ & $6.0 \pm 2.1$ & $5.6 \pm 2.4$ & 0.675 \\
\hline Elbow/(s) ${ }^{*}$ & $5.3 \pm 2.1$ & $4.3 \pm 0.6$ & $5.2 \pm 1.8$ & $5.6 \pm 2.2$ & $5.5 \pm 2.2$ & 0.500 \\
\hline $\begin{array}{l}\text { Hand }(\mathrm{s}) / \\
\text { wrist }(\mathrm{s})^{*}\end{array}$ & $5.7 \pm 2.1$ & $5.3 \pm 1.1$ & $5.6 \pm 2.3$ & $5.7 \pm 2.1$ & $5.8 \pm 2.1$ & 0.930 \\
\hline Knee $(s)^{*}$ & $5.7 \pm 2.1$ & $6.9 \pm 2.0$ & $5.8 \pm 2.1$ & $5.5 \pm 2.1$ & $5.6 \pm 2.2$ & 0.050 \\
\hline
\end{tabular}

* - If the pain occurred on both sides, max. severity was applied; $p$ - test $F$ analysis of variance.

least one knee had lower serum vitamin D concentration than those without pain in any knee. The women who suffered from pain in the cervical spine had higher serum vitamin $D$ concentration than those without pain in that region (Tab. 4).

Table 4. Vitamin D ( $\mathrm{ng} / \mathrm{ml})$ vs. prevalence and severity of pain in the motor system of the examined women

\begin{tabular}{lcccc}
\hline \multirow{2}{*}{$\begin{array}{l}\text { Part of the motor } \\
\text { system }\end{array}$} & \multicolumn{2}{c}{$\begin{array}{c}\text { Vitamin D }(\mathrm{ng} / \mathrm{ml}) \\
\text { vs. prevalence of pain (yes vs. no) }\end{array}$} & \multicolumn{2}{c}{$\begin{array}{c}\text { Vitamin D }(\mathrm{ng} / \mathrm{ml}) \\
\text { vs. severity of pain }\end{array}$} \\
\cline { 2 - 5 } & $\mathrm{b}$ & $\mathrm{p}$ & $\mathrm{b}$ & $\mathrm{p}$ \\
\hline Cervical spine & 0.08 & 0.956 & -0.07 & 0.701 \\
\hline Thoracic spine & 1.60 & 0.008 & -0.22 & 0.429 \\
\hline Lumbar spine & -0.61 & 0.172 & -0.16 & 0.272 \\
\hline Shoulder (s) & -0.18 & 0.750 & -0.03 & 0.881 \\
\hline Elbow(s)* & -0.39 & 0.602 & 0.02 & 0.950 \\
\hline Hand $(\mathrm{s})$ wrist $(\mathrm{s}) *$ & -0.85 & 0.144 & 0.06 & 0.791 \\
\hline Knee(s)* & -0.98 & 0.041 & -0.27 & 0.139 \\
\hline
\end{tabular}

* at least one; $b$ - slope term

The women who suffered from pain in both hands or wrists had significantly lower serum vitamin D concentration than those with one painful hand or wrist. and those without any painful hand or wrist (Fig. 1).

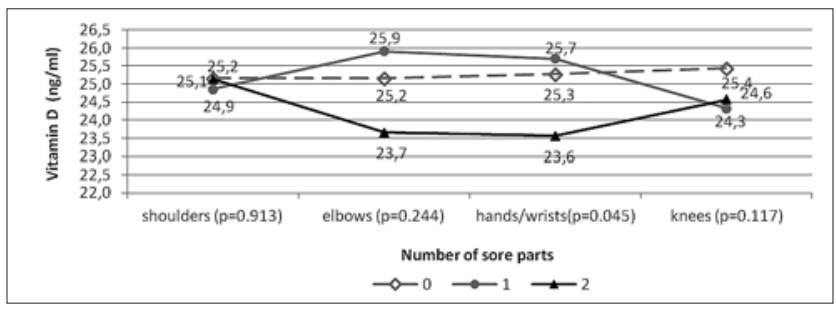

Figure 1. Vitamin $D(\mathrm{ng} / \mathrm{ml})$ vs. number of painful parts of the motor system of the examined women

$p$ - test $F$ analysis of variance

\section{DISCUSSION}

The decreased bone mass, sarcopenia or spine fractures are the most common causes of lower back pain in postmenopausal women. Previously, vitamin D deficiency was suggested to be related with all these disorders. Vitamin $\mathrm{D}$ also shows anti-inflammatory properties, which can be lost when its level decreases and, in turn, musculoskeletal pain may occur $[9,10,11]$.

In the presented study, postmenopausal women from rural areas in Poland suffering from pain involving at least one part of the motor system were significantly younger and lower-educated, compared to the women without pain. The mean WHR ratio was higher in the analysed women with pain than in the women without pain (87.4 vs. 86.6). In addition, it was demonstrated that there was a lower level of vitamin D level in the women with pain, compared to those without any pain $(24.9 \mathrm{ng} / \mathrm{ml}$ vs. $26.0 \mathrm{ng} / \mathrm{ml})$. This finding is in accordance with the earlier results of Lodh et al. [12] in which the patients (women were the vast majority) with back pain had a significantly lower concentration of vitamin $\mathrm{D}$, compared to healthy volunteers. In a study of Brazilian postmenopausal women, the majority of women with vitamin D deficiency did not experience any back pain (69.5 vs. 66.9\%), greater limitation of daily activities, nor any fractures when compared to the women without D hypovitaminosis D [10].

In the population of Malaysia, the median concentration of vitamin $\mathrm{D}$ in the rural women was significantly higher compared to the urban women $(69.5 \mathrm{nmol} / \mathrm{L}$ vs. $31.9 \mathrm{nmol} / \mathrm{L})$ [13]. This difference may be due to the fact that rural women are exposed to the sunlight to a greater degree than urban women. In the study by Nurbazlin et al. [13], the time of exposure to sunlight was mote than 2-fold longer for rural women than for women living in the city. Significantly higher levels of vitamin D in rural adults from India were observed when compared to urban adults, in both male and female groups [14]. The intensity of sunlight, depending on the latitude, influences the synthesis of vitamin D in the body. In a study of farming families in Denmark, farmers and their male children had the highest exposure to sun light during the summer [15], whereas the levels of vitamin D did not differ between family members. However, at the end of the summer, $16 \%$ of the participants had an insufficient vitamin D level, and during the winter $-61 \%$ [15]. Another study confirming the lower vitamin D level in rural women than in urban women was performed on Spanish postmenopausal women [16]. The authors also observed lower values of bone mineral density (BMD) in the lumbar spine, and a higher occurrence of spine fractures in rural women than in those from the city. On the other hand, in the study by Afsar et al. [17] analysing levels of vitamin D in patients with low back pain, menopausal women had higher vitamin $\mathrm{D}$ concentrations than those at reproductive age. To the contrary, Thörneby et al. [18] found no correlation in vitamin D levels between patients with chronic low back pain and controls. These results should be treated with caution, however, because of the small groups analysed.

In the presented study, on analysing the impact of vitamin $\mathrm{D}$ on the prevalence of pain, its important effect on the thoracic spine as well as knees, was demonstrated. The women with pain in at least one knee had a lower serum vitamin D level than those without knee pain. Earlier studies showed a relationship between the serum vitamin $\mathrm{D}$ levels in postmenopausal women with osteoporosis, as well as knee extension strength and its functional capacity [19], since vitamin D may influence neuromuscular transmission. Surprisingly, in the analysed group of women in the current study, no relationship was found between BMI and pain in the musculoskeletal system. The women with pain had a comparable BMI to those without pain. 
Taking into consideration the results of this study, reports from other studies as well as the fact that in Poland, between November and March there is insufficient amount of sunshine for vitamin D synthesis, its supplementation seems to be justified in all the age groups, especially in postmenopausal women. According to Holick et al. [20], several minutes of exposure to sunlight three times per week, a better dietary regime and vitamin $\mathrm{D}$ supplementation, may guarantee a sufficient level. Older women with osteoporosis taking vitamin D supplements have increased muscle strength [21]. Analysis of a large cohort of agrarian postmenopausal women from Nebraska, USA, showed that women using vitamin D supplements, had one-sixth chance of the vitamin $\mathrm{D}$ value below the reference limit than those not using supplements [22]. However, interestingly, the previous data concerning the impact of calcium and vitamin $\mathrm{D}$ supplementation on BMD showed that supplementation with calcium had more success in reducing the rate of BMD loss from the total hip in women than supplementation with 25-OHD3. The effect of calcium, however, was greater when the serum vitamin $\mathrm{D}$ levels were lower [23]. Cooper et al. [24] reported that the change in BMD in early postmenopausal women did not differ significantly between women taking calcium alone and those taking calcium and vitamin D2 supplements together.

In conclusion, vitamin $\mathrm{D}$ is important for the presence and severity of pain involving the neck and thoracic spine, knees, hands or wrists, but not for the lumbar spine, shoulders and elbows.

\section{CONCLUSIONS}

1) Postmenopausal women working in agriculture and suffering from pain involving at least one part of the motor system are younger and lower educated, they also have higher abdominal obesity and lower serum vitamin D concentration, compared to those without pain in any part of the motor system.

2) Decreased serum vitamin D concentration in postmenopausal women working in agriculture is significant for:

a) higher prevalence of pain in the thoracic spine and more severe pain in the cervical spine, but neither prevalence nor severity of pain in the lumbar spine;

b) higher prevalence of pain in both hands or wrists;

c) higher prevalence and more severe pain in at least one knee;

d) neither prevalence nor severity of pain in the shoulders and elbows.

3) Knowledge of proper vitamin D supplementation should be promoted among postmenopausal women.

\section{Acknowledgements}

This study was conducted at the Institute of Rural Health in Lublin, Poland, as a part of the 'Programme of Nationwide Health Screening for Residents of Rural Areas 2015-2016', supported and co-organized by the Contribution Fund of Farmers' Social Insurance and the Agricultural Social Insurance Fund.

\section{REFERENCES}

1. Brannon PM. Key questions in Vitamin D research. Scandinavian Journal of Clinical and Laboratory Investigation Supplementum, 2012; 243: 154-162.

2. Arnson Y, Amital H, Shoenfeld Y. Vitamin D and autoimmunity: new aetiological and therapeutic considerations. Ann Rheum Dis 2007; 66: 1137-1142.

3. Lips P, Graafmans WC, Ooms ME, Bezemer PD, Bouter LM. Vitamin $\mathrm{D}$ supplementation and fracture incidence in elderly persons. A randomized, placebo-controlled clinical trial. Ann Intern Med. 1996 Feb 15;124(4):400-6.

4. Siddque SA, Malik YM. Frequency of Vitamin D deficiency in patients of low backache. Ann. Pak. Inst. Med. Sci. 2011; 7(4): 208-212

5. Al Faraj S, Al Mutairi K. Vitamin D deficiency and chronic low back pain in Saudi Arabia. Spine 2003;28:177-9

6. Ghai B, Bansal D, Kanukula R, Gudala K, Sachdeva N, Dhatt SS, Kumar V. Vitamin D Supplementation in Patients with Chronic Low Back Pain: An Open Label, Single Arm Clinical Trial. Pain Physician. 2017 Jan-Feb;20(1):E99-E105.

7. Grigorie D, Sucaliuc A, Ivan M, Neacsu E, Popa O, Diaconescu A. High prevalence of vitamin D deficiency in 1048 Romanian postmenopausal women with osteoporosis. Acta Endocrinologica (Buc). 2008;IV:33-45.

8. Rkain H, Bouaddi I, Ibrahimi A, Lakhdar T, Abouqal R, Allali F, Hajjaj-Hassouni N. Relationship between vitamin D deficiency and chronic low back pain in postmenopausal women. Curr Rheumatol Rev. 2013;9(1):63-7.

9. Visser M, Deeg DJ, Lips P; Longitudinal Aging Study Amsterdam. Low vitamin $\mathrm{D}$ and high parathyroid hormone levels as determinants of loss of muscle strength and muscle mass (sarcopenia): the Longitudinal Aging Study Amsterdam. J Clin Endocrinol Metab. 2003 Dec;88(12):5766-72

10. e Silva AV, Lacativa PG, Russo LA, de Gregório LH, Pinheiro RA, Marinheiro LP. Association of back pain with hypovitaminosis D in postmenopausal women with low bone mass. BMC Musculoskelet Disord. 2013 Jun 12;14:184. doi: 10.1186/1471-2474-14-184.

11. Lacativa PG, Farias ML. Osteoporosis and inflammation. Arq Bras Endocrinol Metabol. 2010 Mar;54(2):123-32.

12. Lodh M, Goswami B, Mahajan RD, Sen D, Jajodia N, Roy A. Assessment of Vitamin D status In Patients of Chronic Low Back Pain of Unknown Etiology. Indian J Clin Biochem. 2015 Apr;30(2):174-9. doi: 10.1007/ s12291-014-0435-3.

13. Nurbazlin M, Chee WS, Rokiah P, Tan AT, Chew YY, Nusaibah AR, Chan SP. Effects of sun exposure on $25(\mathrm{OH})$ vitamin D concentration in urban and rural women in Malaysia. Asia Pac J Clin Nutr. 2013;22(3):391-9. doi: 10.6133/apjen.2013.22.3.15.

14. Harinarayan CV, Ramalakshmi T, Prasad UV, Sudhakar D. Vitamin D status in Andhra Pradesh: A population based study. Indian J Med Res 2008; 127: 211-218.

15. Bodekær M, Petersen B, Thieden E, Philipsen PA, Heydenreich J, Olsen $\mathrm{P}$, Wulf HC. UVR exposure and vitamin D in a rural population. A study of outdoor working farmers, their spouses and children. Photochem Photobiol Sci. 2014 Nov;13(11):1598-606. doi: 10.1039/c4pp00188e.

16. Gómez-de-Tejada Romero MJ, Navarro Rodríguez MD, Saavedra Santana P, Quesada Gómez JM, Jódar Gimeno E, Sosa Henríquez M. Prevalence of osteoporosis, vertebral fractures and hypovitaminosis D in postmenopausal women living in a rural environment. Maturitas. 2014 Mar;77(3):282-6. doi: 10.1016/j.maturitas.2013.12.011.

17. Afsar SS, Idrees M, Gulzar M. Levels of vitamin D in patients with low backache. Gomal Journal of Medical Sciences July-September 2014; 12(3): 151-155.

18. Thörneby A, Nordeman LM, Johanson EH. No association between level of vitamin D and chronic low back pain in Swedish primary care: a cross-sectional case-control study. Scand J Prim Health Care. 2016 Jun;34(2):196-204. doi: 10.1080/02813432.2016.1183557.

19. Brech GC, CiolacEG, Peterson MD, Greve JM. Serum 25-hydroxyvitamin D levels are associated with functional capacity but not with postural balance in osteoporotic postmenopausal women. Clinics (Sao Paulo). 2017 Jan 1;72(1):11-16. doi: 10.6061/clinics/2017(01)03.

20. Holick MF. Sunlight and vitamin D for bone health and prevention of autoimmune diseases, cancers, and cardiovascular disease. Am J Clin Nutr. 2004; 80(6):1678S-1688S

21. Schacht E, Ringe JD. Alfacalcidol improves muscle power, muscle function and balance in elderly patients with reduced bone mass. Rheumatol Int. 2012 Jan;32(1):207-15. doi: 10.1007/s00296-010-1607-y.

22. Lappe JM, Davies KM, Travers-Gustafson D, Heaney RP. Vitamin D status in a rural postmenopausal female population. J Am Coll Nutr. 2006 Oct;25(5):395-402.

23. Peacock M1, Liu G, Carey M, McClintock R, Ambrosius W, Hui $\mathrm{S}$, Johnston CC. Effect of calcium or $25 \mathrm{OH}$ vitamin D3 dietary supplementation on bone loss at the hip in men and women over the age of 60. J Clin Endocrinol Metab 2000;85:3011-9.

24. Cooper L, Clifton-Bligh PB, Nery ML, Figtree G, Twigg S, Hibbert E, Robinson BG. Vitamin D supplementation and bone mineral density in early postmenopausal women. Am J Clin Nutr. 2003 May;77(5):1324-9. 